\title{
Çocuklarda Prosedürel Ağrı Yönetiminde Dikkati Başka Yöne Çekme Yöntemlerinin Kullanımı
}

\author{
Using of Distraction Methods on Procedural Pain Management of \\ Pediatric Patients
}

\begin{abstract}
Sevil İnal a ${ }^{\text {Nejla Canbulat }}{ }^{\text {b }}$
ÖZET Kan alma, enjeksiyon uygulama gibi medikal prosedürler çocukların en büyük ağrı kaynaklarından biridir. Ağrı çocukların aşı, enjeksiyon ve kan alma uygulaması gibi medikal prosedürlerden korkmasına, bazı medikal prosedürlere karşı gönülsüzlüğü hatta tedavinin ihmal edilmesine yada gecikmesine neden olabilmektedir. Bu nedenle hemşire, çocuklarda ağrının uzun dönem olumsuz etkilerini azaltmak ve ağrılı prosedürlerin fiziksel ve emosyonel etkilerini gidermek için ağrılı prosedürleri yönetmelidir. Çocuklarda medikal prosedürler sırasında oluşabilecek ağrı ve anksiyeteyi azaltmaya yönelik farmakolojik ve non-farmakolojik yöntemleri kapsayan pek çok yaklaşım vardır. Son yıllarda, hemşirelerin ağrılı prosedürlerde ağrıyı gidermeye yönelik non-farmakolojik yöntemlerin kullanımı ile ilgili araştırmalar artmıştır. Medikal prosedürler sırasında oluşan ağrıyı gidermede en sık kullanılan yöntemlerden biri dikkati başka yöne çekmedir. Dikkati başka yöne çekme yöntemi, ağrıyı azaltmak için hastanın dikkatini başka bir uyarana yoğunlaştırma girişimidir ve beynin stimulasyona dikkatini yoğunlaştırma ile ilgili kapasitesinin sınırlı olduğu hipotezine dayanmaktadır. $\mathrm{Bu}$ makalede sıklıkla kullanılan dikkati başka yöne çekme yöntemleri tartışılacaktır.

Anahtar Kelimeler: dikkati başka yöne çekme yöntemleri, ağrı yönetimi, hemşirelik, çocuk hasta
\end{abstract}

\begin{abstract}
Medical procedures such as vaccine administration, phlebotomy and injections are the most important sources of pain for children. Pain causes children to be frightened of needles and this leads to be unwillingness to medical procedures, even can be neglected or delayed to treatment and care. Thus, the nurse should be able to manage painful procedures to reduce emotional and physical effects of painful procedures and to avoid long-term results of pain in children. There are many different approaches to the treatment of procedural pain and anxiety of children during medical procedures, including pharmacological and non-pharmacological methods. In recent year research focusing on nurses' use of non-pharmacological methods for pain relief of children's has increased. Present widely used non-pharmacological method for pain relief of children during painful medical procedures is distraction method. Distraction is a nursing attempt focusing patient's attention to any other stimulants to control and reduce pain better. The rationale for the pain-reducing effects of distraction hypothesized that the brain has a limited capacity of focusing attention on stimulation. In this article frequently used ditraction method will be discussed.
\end{abstract}

Key words: Distraction methods, pain management, nursing, pediatric patient

\footnotetext{
${ }^{a}$ Doç Dr., İstanbul Üniversitesi Sağlık Bilimleri Fakültesi,Yazışma Adresi: Doç. Dr. Sevil İnal, İstanbul Üniversitesi Sağlık Bilimleri Fakültesi, Bakırköy/İstanbul e-mail: inalsevil@ gmail.com

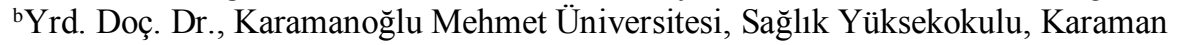

e-mail: ncanbulat@gmail.com
} 


\section{GíRiș}

Ağrılı medikal prosedürlerin çocuğa etkisi

Kan alma, enjeksiyon uygulaması, aş1 uygulaması gibi ağrılı medikal prosedürler, çocukların en büyük korkularından biridir. $\mathrm{Bu}$ korkular çoğu zaman çocuk ve ebeveynlerde aş1 uygulaması, kan alma gibi medikal prosedürlere karşı isteksizliğe yol açmakta ve çocuğun sonraki tedavi ve bakım deneyimini etkilemektedir. Ağrılı medikal prosedürler hastanede yatan çocuklarda, en büyük ağrı ve korku kaynaklarından biridir. Özellikle kronik hastalıklı çocuklar tanı, tedavi ve izlem sürecinde çok sayıda ağrılı prosedürle karşı karşıya kalmaktadır ${ }^{1,2}$.

Sağlıklı çocuklar bile kan alma ve tekrarlayan çok sayıda aşı uygulaması gibi nedenlerle ağrı deneyimlemektedir. Örneğin çocuklar 6 yaşına gelene kadar 20'den fazla aş1 uygulamasına bağlı enjeksiyon uygulaması gerekmektedir $^{(3,4)}$. Araştırmalar, çocukların bu medikal prosedürler sırasında hem ağrı hem de anksiyete yaşadığını göstermektedir ${ }^{2}$.

Uluslar arası Ağrı Araştırmaları DerneğininInternational Association for the Study of Pain ${ }^{5}$ sıklıkla kabul gören tanımına göre ağrı; vücudun belli bir bölgesinden kaynaklanan, doku hasarına bağlı olan ya da olmayan, kişinin geçmişteki deneyimlerinden etkilenen ve istenmeyen durumu uzaklaştırmaya yönelik, hoş olmayan biyokimyasal durum ya da deneyim olarak tanımlanmıştır. Bunun yanı sıra ağrı büyük oranda bireysel özelliklerle ilişkili, fizyolojik, davranışsal, duygusal, gelişimsel ve sosyokültürel bileşenlerle ilişkili multifaktöriyel bir deneyimdir ${ }^{2}$.

Ağrı kendini ifade edemeyecek kadar küçük çocukları bile etkilemektedir. Çocuklarda enjeksiyon korkusu, tedavinin reddedilmesine, bazı gerekli tetkiklerin yapılmamasına ya da gecikmesine neden olabilmektedir ${ }^{6}$. Ağr1 korkusunun adolesanlarda siklıkla tedavide gecikmeye neden olduğu bildirilmektedir. Erişkinlerin yaklaşık \% 40'ının enjeksiyon korkusu nedeniyle kan örneği alınmasını reddettikleri bilinmektedir ${ }^{7}$.

Dünyanın çeşitli ülkelerinde bazen ailelerin çocuğun canının acımasını önlemek için aşı uygulamasından vazgeçmeyi seçtikleri görülmektedir. Bu nedenle, çocuklarda medikal prosedürler sırasında ağrıyı azaltıcı etkili yöntemler kullanmak çok önemlidir. Halihazırda bazı birimlerde kan alma gibi medikal prosedürlere bağlı ağrıyı azaltmak için; HSP 2015;2(3):372-378 lokal anestezikler kullanılmakta, kullanılan anestezikler ağrıyı azaltabilmekte ya da giderebilmektedir ${ }^{8,9}$. Ancak bu lokal anesteziklerin maliyetleri fazla, etki süreleri uzun ve vazokonstriksiyona bağlı olarak damara girme işleminde başarıyı azaltan etkiye sahip olduğu bilinmektedir ${ }^{(10)}$.

Son y1llarda hemşirelik araştırmaları çocuklarda prosedüral ağrının azaltılmasında nonfarmakolojik yöntemlerin kullanılmasına odaklanmıştır. Non-farmakolojik yöntemler ağr1 kontrolünde tek başına kullanılabileceği gibi farmakolojik girişimlerle birlikte de kullanılabilmektedir. Uygun şekilde kullanıldığında non-farmakolojik yöntemler prosedürel ağrının giderilmesinde etkili olabilmektedir. Çocuklarda ağrı kontrolünde kullanılan non-farmakolojik yöntemler; destekleyici yöntemler, bilişsel/davranışsal yöntemler ve fiziksel yöntemler olmak üzere üç ana grupta toplanabilir. Destekleyici yöntemler, çocukların psikososyal bakımını kapsar. Bu yöntemde, video izleme, kitap okuma, ailenin ağrılı prosedür sırasında çocuğun yanında kalmasını sağlama gibi teknikler uygulanır. Fiziksel yöntemler arasında dokunma, pozisyon verme, masaj, cilt stimülasyonu, sicak ve soğuk uygulama sayılabilir. Bilişsel/davranışsal yöntemler ise ağrının algısal, duyusal, davranışsal boyutu olduğu savına dayanır ve gevşeme, dikkati başka yöne çekme gibi yöntemleri kapsar ${ }^{2,11}$.

Dikkati başka yöne çekme tekniği, ebeveynler ve sağlık çalışanları tarafindan çeşitli şekillerde, medikal prosedürlerle ilişkili ağr1 ve anksiyeteyi azaltmada kullanılmış ve etkili olduğu belirlenmiştir ${ }^{1,2,12-22}$. Dikkati başka yöne çekme teknikleri hem akut hem kronik ağrıda etkin şekilde kullanılabilen bilişseldavranışsal yöntemlerdendir ${ }^{23}$.

$\mathrm{Bu}$ makalenin amacı, çocuklarda ağrılı medikal prosedürler sırasında oluşan ağrıyı azaltmada dikkati başka yöne çekme yöntemlerini literatür 1şığında irdelemek ve ülkemizde çocuklarda ağrılı medikal prosedürlerin yönetiminde hemşire ve diğer sağlık çalışanlarına dikkati başka yöne çekme teknikleri ve kullanım yolları konusunda bilgi vermektedir.

\section{Dikkati başka yöne çekme yöntemleri}

Dikkati başka yöne çekme yöntemi, hastanın dikkatini başka bir yere odaklayarak ağrıyı daha iyi kontrol etme ve azaltmayı sağlayan bir 
hemşirelik girişimidir. Dikkati başka yöne çekmek için kullanılan birçok yöntem vardır. Bunlardan bazıları; çizgi film izletme ${ }^{13,14}$, balon şişirtme ${ }^{15}$, köpük üfleyerek balon oluşturma ${ }^{16,17}$, girişimle alakasız şeyler konuşma ${ }^{18,19}$ sanal gerçeklik gözlüğü kullanma ${ }^{20}$, müzik dinletme ${ }^{1}$, kaleydoskop kullanma ${ }^{21}$ ve dikkati başka yöne çekme kartlarını ${ }^{22}$ kullanmadır. Her yöntemin özellikleri ve kanıta dayalı etkileri aşağıda incelenmiştir.

Çizgi film izletme: Cohen ve arkadaşları $(1997)^{14} 4-6$ yaş arası çocuklarla yaptıkları bir çalışmada aşı uygulanan çocuklarda işlem sırasında sevdiği çizgi filmleri izlemesinin, aşılama sırasında oluşan ağrı ve stresi azaltmada etkili ve pratik bir yöntem olduğunu göstermişlerdir. Weisenberg ve arkadaşları tarafından erişkinlerde yapılan bir çalışmada ise komik filimler izlemenin ağrı toleransını büyük ölçüde azalttığı bulunurken ${ }^{23}$, De Wied ve Verbaten tarafindan yapılan başka bir çalışmada ise duygusal filmlerin orta düzeyde ağr1 tolerans1 sağladığını bulmuşlardır ${ }^{24}$. Bunun yanı sıra, Cassidy ve arkadaşları IM yolla karma aşı uygulanan 5 yaş grubu çocukları, televizyonda müzikli çizgi film izleme $(n=29)$, ve televizyon ekranına bakma $(n=33)$ olmak üzere 2 gruba ayırmış, aşı uygulaması sırasında çizgi film izlemenin ağrıy azaltmada etkili olmadığını bildirmişlerdir ${ }^{13}$. Öte yandan Landolt ve arkadaşları tarafından yanıklı çocuklara pansuman değişimi sırasında çizgi film izlemenin çocuklar tarafindan algılanan ağrı düzeyinde istatistiksel olarak anlamlı bir fark yaratmadığ 1 belirtilmektedir ${ }^{25}$. Dovney ve Zun $(2012)^{26}$ acil ünitesinde çeşitli ağrılı prosedürler sırasında ağrıyı giderme yöntemi olarak çizgi film izlemeyi kullandıkları çalışmalarında, çizgi film izlemeden 5 dakika önce, izleme sirasında ve çizgi film izlemeden $5 \mathrm{dk}$ sonra ağrıyı değerlendirmişler, çizgi film izlemenin ağrıyı azaltmada etkili olduğu sonucuna varmışlardır. Bellini ve arkadaşları (2006) ${ }^{27}$ 7-12 yaş arası 69 çocukla yaptıkları ve çocukları, müdahalesiz grup, anneleri tarafından aktif dikkati başka yöne çekme tekniği uygulanan grup ve (pasif) çizgi film izleme olmak üzere 3 gruba ayırdıkları çalışmalarında, çizgi film uygulanan grubun ağrı skorlarının en düşük olduğunu, anneleri tarafindan aktif dikkati başka yöne çekme tekniği kullanıların ikinci düşük ağrı skoruna sahip olduğunu, en yüksek ağrı skorunun ise müdahalesiz grupta olduğunu HSP 2015;2(3):372-378 görmüşlerdir ${ }^{27}$. Wang ve arkadaşları da $(2008)^{28}$ yaptıkları araştırmada çocuklara çeşitli ağrılı prosedürler uygulanacak 8-9 yaş aras1 300 çocuğu 3 gruba ayırmış, bir gruba prosedür sırasında psikolojik destek sağlamış, bir gruba işlem sırasında çizgi film izletmiş, bir gruba da hiçbir müdahale yapmadan işlemi gerçekleştirmişlerdir. Sonuçta ağrilı medikal prosedür sırasında çizgi film izleyen çocukların en düşük ağrı ortalamasına sahip olduğunu, 2. Sirada psikolojik destek sağlanan grubun olduğunu, kontrol grubunun ise en yüksek ağr1 skoru ortalamasına sahip olduğunu görmüşlerdir. Görüldüğü gibi 2 araştırmada çizgi film izlemenin ağrıyı azaltmada etkili olmadığı bildirilse de bu çalışmalardan biri çok ağrılı bir girişim olan yanık pansumanı değişimi sırasında uygulanmıştır ${ }^{(25)}$, diğeri ise sadece 5 yaş grubu çocukların oluşturduğu bir örneklemde gerçekleştirilmiştir. Genel olarak yapılan diğer çok sayıda randomize kontrollü çalışma ağrılı prosedürler sırasında çizgi film izlemenin çocukların ağrı algısını azalttığını ve ağrılı prosedürler sırasında kullanılabileceğini göstermektedir.

Balon şişirtme ve köpükten balon yapma: Manne ve ark $(1990)^{(29)}$, kan alma sirasinda balon şişirmenin aile ve çocuğun stresini azaltmada etkili bir yöntem olduğunu bildirmiştir. Yapılan diğer çalışmalarda aşı uygulaması sırasında köpükten balon yapmanın etkili olduğu bildirilmiştir. French ve arkadaşları $(2000)^{(16)}$, Manne ve arkadaşları $(1990)^{(29)}$ Blount ve arkadaşları (1992) $)^{(30)}$ okul öncesi çağdaki çocuklarda rutin immünizasyon sirasında köpükten balon yapmayı derin nefes alma ve üfleme yöntemi olarak kullanmışlar ve ağrıyı azaltmada etkili olduğunu bulmuşlardır. Gupta ve arkadaşları da (2006) ${ }^{(31)}$ yaptıkları randomize kontrollü çalışmada, 6-12 yaş arası 75 çocuğu 25 kişilik 3 eşit gruba ayırmış, birinci gruptaki çocuklara herhangi bir yöntem kullanmadan damar yolu açma girşimi uygulamış, 2. grup çocuklara prosedür sirasında diğer eliyle lastik topu sikıp gevşetmesi istenmiş, 3. Grup çocukların ise prosedür sirasında balon şişirmesi sağlanarak dikkati başka yöne çekme tekniği kullanılmıştır. Araştırmacılar balon şişiren gruptaki ve lastik top grubundaki çocukların ağrı düzeylerinin 
kontrol grubuna göre anlamlı şekilde düşük olduğunu, en düşük ağrı düzeylerinin balon şişiren grupta olduğunu görmüşlerdir. $\mathrm{Bu}$ araştırma sonuçlarından hareketle balon şişirmenin ağrılı medikal prosedürler sırasında etkin bir şekilde kullanılabileceğ $i$ söylenebilir ${ }^{(31)}$.

Ebeveyn tarafindan dikkatin başka yöne çekilmesi (Girişimle alakasız şeyler konuşma): Gonzalez ve arkadaşları (1993) ${ }^{(18)}$ ile Mason ve arkadaşları (1999) ${ }^{(19)}$ tarafından yapılan iki çalışmada ağrılı enjeksiyon uygulaması sırasında ebeveynin çocukla girişimle ilgili olmayan konularda konuşmasının ağriyı azalttığı bildirilmiştir. Bellieni ve arkadaşları (2006) tarafindan yapılan bir başka çalışmada ise kan alma sirasinda televizyon izlemenin çocukların ağrısını azaltmada ebeveyn tarafindan uygulanan dikkati başka yöne çekmeye göre daha etkili olduğu belirlenmiş olsa da, araştırmacılar ebeveynin duygusal katılımı nedeniyle ebeveyn tarafindan uygulanan dikkati başka yöne çekme tekniğinin daha az etkin olabileceğini düşünmüşlerdir ${ }^{(27)}$. $\mathrm{Bu}$ sonuçlardan hareketle, ebeveyn tarafindan çocukla konuşularak dikkatin başka yöne çekilmesi çocuklarda ağrılı prosedürler sırasında kullanılabileceği söylenebilir.

Müzik dinletme: Hemşireler, uzun yıllardır hastalarda ağrının azaltılmasında müziği kullanmışlardır. Çok sayıdaki çalışma müzik dinlemenin ağriy1, anksiyeteyi ve agresif davranışları azalttığını ortaya koymaktadır ${ }^{(32)}$. Press ve arkadaşları (2003) ${ }^{(33)}$ çalışmalarında acil servise başvuran 6-16 yaş grubu çocuklarda kan alma işlemi sırasında müzik dinletmenin etkisine bakmış, ancak ağrının azaltılmasında kontrol grubuna göre anlamlı farkl111k bulunmamıştır. Arts ve arkadaşları (1994) ${ }^{(1)}$ cerrahi girişim planlanan 4-16 yaş grubu çocuklarda venöz kan alma sırasında oluşabilecek ağrının azaltılmasında müzik dinletme, plasebo krem ve lidocain-prilocain içeren kremle (EMLA krem) karşılaştırmışlardır. Araştırma sonucuna göre; EMLA kremin müzik dinletme ve plasebo kreme oranla daha etkili olduğu ancak 7-11 yaş grubu dışında anlamlı farklılık olmadığı belirlenmiştir. Fowler-Kerry ve Lander $(1987)^{(34)}$ çalışmalarında kulaklıkla müzik dinletmenin çocuklarda ağrılı medikal prosedürler sırasında oluşan ağriyı azaltmada etkili olduğunu bildirmiştir. Balan ve arkadaşları (2009) ${ }^{(35)}$ venöz girişim gereken 5-12 yaş grubu çocuğu, 3 gruba ayırdıkları randomize kontrollü çalışmalarında, bir gruba lokal anestetik krem, bir gruba plasebo bir gruba da mizik dinletme metoduyla dikkati başka yöne çekme tekniği uygulamışlardır. Sonuçta hem müzik dinletiken hem de lokal anestetik krem kullanılan çocuklarda ağrı skorunun plasebo grubundan anlamlı şekilde düşük olduğunu, lokal anestezi grubu ve müzik grubunun ağrı skorları arasında anlamlı fark olmadığını görmüşlerdir. Caprilli ve arkadaşları (2007) ${ }^{(36)}$ müzik dinletilen grup ve kontrol grubu olmak üzere 4-13 yaş aras1 108 çocuğu 2 gruba ayırdıkları çalışmalarındakan testi yapılacak, müzik grubu çocukların ağrı skorlarının kontrol grubundan belirgin şekilde düşük olduğunu göstermişlerdir. Kristjansdottir ve arkadaşları (2011) $)^{(37)}$ inaktif polio aşıs1 uyguladıkları 128 adolesanı 3 gruba ayrıdıkları randomize kontrollü çalışmada, 1. Gruba kulaklıkla müzik dinletmiş, 2. Gruba kulaklık olmaksızın ortamda müzik dinletmişüçüncü gruba ise herhangi bir yöntem kullanılmaksızın aşı uygulamıştır. Müzik dinletilen her iki grubun ağr1 skorlarının kontrol grubundan anlamlı ölçüde düşük olduğunu, en düşük ağr1 skorunun ise kulaklikla müzik dinletilen grupta olduğunu görmüşlerdir. Nguyen ve arkadaşları (2010) $)^{(38)}$ lomber ponksiyon yapılalacak 7-12 yaş arası 40 lösemi hastasını 2 gruba ayırdıkları randomize kontrollü çalışmalarında, grubu 20 müzik 20 kontrol grubu olmak üzere 2 gruba ayırmış, müzik grubunun ağrı skorlarının anlamlı şekilde düşük olduğunu, bunun yanı sıra nabiz ve solunum sayılarının da hem uygulama sirasinda hem de sonrasinda anlamlı şekilde daha düşük olduğunu bulmuşlardır. Literatür incelemesi, ağrılı medikal prosedürler sırasında müzik dinletmenin ağrıyı azaltmada güvenle kullanılabileceğini göstermetedir. 
Sanal gerçeklik gözlüklerinin kullanımı: Sanal gerçeklik (Virtual Reality Glass) hastayı gerçek hayattan izole etmek için hastaya takılan bir başlıkla hastanın gözlerine lens yaklaştırılarak bilgisayardan alınan görüntülerin izletilmesi yöntemidir. Ayrıca hastaya kulaklık takılarak hastane seslerini alg1lamas1 engellenir ve rahatlatıcı sesler dinletilir. Sonuç olarak hastanın 3 boyutlu olarak başka bir dünyayı ziyaret ettiği hissi verilmektedir. Sanal gerçeklik özellikle yanıklı hastalarda ağrının azaltılmasında kullanılan bir yöntem olarak dikkat çekmektedir. Akut yanıklı çocuk hastalarda da etkin olduğu bildirilmiştir ${ }^{(39)}$. Bunun yanında; Sander Wint ve arkadaşları $(2002)^{(40)}$ yaptıkları lomber ponksiyon yapılan kanserli adolesanlarda sanal gerçeklik gözlüğü kullandıkları randomize konrtollü çalışmada, sanal gerçeklik gözlüğü kullanılan adolesanların ağrı ölçeklerinden daha düşük puan aldıklarını ancak aralarında istatistiksel anlamlılık bulunmadığını belirtmiştir.

Yapılan az sayıda çalışma sanal gerçeklik gözlüklerinin kullanımının dikkati başka yöne çekmede etkili olduğunu gösterse de bu konuda yapılacak daha fazla araştırmaya gereksinim olduğu söylenebilir.

Kaleydoskop kullanımı: Kaleydoskop (çiçek dürbünü) içine bakıldığında renkli desenler görülen bir oyun materyalidir. $\mathrm{Bu}$ desenler, 1şığın yansımasıyla elde edilir ve dürbün hareket ettirildikçe sürekli değişir. Dürbünün içerisi siyah ya da koyu bir renge boyalıdır. İçinde aralarında 60 derecelik eğimle birbirine bitişik iki ayna bulunur. Aynaların arasında renkli cam parçaları, tüyler, pullar, ince boncuklar vb. gibi malzemeler bulunur. Bu dürbünün bir ucundan bakıldığında şekil değiştiren çokgenler, çoğunlukla bir daha aynı olmayacak görüntüler görülmektedir. Vessey ve ark $(1994)^{(41)}$ okul öncesi ve okul çocuklariyla, Carlson ve ark (2000)'nın ${ }^{(42)}$ çocuk ve adolesanlarla, Güdücü Tüfekçi ve ark (2009) ${ }^{(21)}$ ve Hasanpour ve ark. (2006)'nın ${ }^{(43)}$ okul çağı çocuklarla yaptıkları çalışmalarda kan alma sırasında oluşabilecek ağrının azaltılmasında kaleydeskop kullanımının etkin olduğu bildirilmiştir. Elde edilen sonuçlar Kaleydoskop'un çocukların dikkatini ağrılı prosedürden uzaklaştırmada ve ağr1 algısını azaltmada etkin bir şekilde kullanılabilec ĕgini göstermektedir.
Dikkati başka yöne çekme kartlarının kullanımı: Dikkati başka yöne çekme kartları, çeşitli gizli resim ve desenleri içeren resimli kartlardan oluşmaktadır (Flippits ${ }^{\circledR}$, MMJ Labs, Atlanta; GA, USA). Bu gizli resim ve desenler çocuğun ancak dikkatlice baktığında görebileceği niteliktedir. İşlem sırasında çocuğa kartlarla ilgili sorular sorulmaktadir. Ör. Resimde kaç tane uğur böceği var? Resimdeki fili görebiliyor musun? Resimde kaç tane mavi çiçek var? gibi. Dikkati başka yöne çekme kartları oldukça yeni bir uygulamadır ve konuyla ilgili az sayıda araştırma bulunmaktadırİnal ve Kelleci'nin (2012) ${ }^{(22)}$ 6-12 yaş grubu çocuklarla yaptığı randomize kontrollü çalışmada, araştırmacılar kan alma işlemi sırasında uyguladıkları dikkati başka yöne çekme kartlarının, prosedürel ağrıyı ve anksiyeteyi azaltmada etkili olduğunu bildirmişlerdir. Ayrıca hem görsel hem de işitsel uyaranların birlikte kullanımının dikkati başka yöne çekmede daha etkili olacağını vurgulamaktadırlar. Ancak farklı medikal prosedürlerde yöntemin etkinliğini ortaya koyacak daha fazla araştırmaya ihtiyaç vardır.

Sonuç olarak; kan alma sırasında ağrıyı azaltmak için kullanılacak yöntem, etkili olabilen, yeniden kullanılabilir, ucuz ve kolay uygulanabilir, çocuklar tarafindan kolay tolere edilebilir nitelikte olmalıdır. Makalede sözü edilen dikkati başka yöne çekme yöntemleri etkin, fazla maliyet gerektirmeyen ve uygulaması kolay yöntemlerdir. $\mathrm{Bu}$ nedenle hemşireler çalıştıkları birimlerde ağrılı medikal prosedürler sirasında ağriyı gidermede makalede sözü edilen dikkati başka yöne çekme yöntemlerini kullanabilir. Ağrıy azaltmaya yönelik uygulanan bu girişimlerin hem tedavi hem de bakım girişimleri sırasında oluşacak ağrıyı azaltmasının tedavi ve bakıma uyumu arttırarak uzun ve kısa dönem hasta sonuçlarını olumlu etkileyeceği unutulmamalıdır.

\section{KAYNAKLAR}

1. Arts SE, Abu-Saad HH, Champion GD, Crawford MR, Juniper KH, Ziegler JB, Fisher RJ. Age-related response to lidocaine-prilocaine (EMLA) emulsion and effect of music distraction on the pain of intravenous cannulation. Pediatrics, 1994;93,797-801.

2. Uman LS, Birnie KA, Noel M, Parker JA, Chambers CT, McGrath PJ, Kisely SR. 
Cochrane Database Syst Rev., 2013;10 (10): doi: 10.1002/14651858.CD005179.pub3.

3. CPS 2004(Canadian Paediatric Society). www.cps.ca 2004. Erişim:29.11.2013.

4. SB (Sağlı Bakanlığı) www.saglik.gov.tr. Erișim:29.11.2013

5. IASP (2004) Task Force on Taxonomy. Classification of Chronic Pain. Second Edition. Seattle: IASP Press.

6. Spielberg F, Branson BM, Goldbaum GM. Overcoming barriers to HIV testing: preferences for new strategies among clients of a needle exchange, a sexually transmitted disease clinic, and sex venues for men who have sex with men. J Acquir Immune Defic Syndr., 2003;32 (3):318-327.

7. Wong ML, Chia KS, Yam WM, Teodoro GR, Lau KW. Willingness to donate blood samples for genetic research: a survey from a community in Singapore. Clin Genet. Jan, 2004;65 (1):45-51.

8. Luhmann J, Hurt S, Shootman M, Kennedy R. A comparison of buffered lidocaine versus ELA-Max before peripheral intravenous catheter insertions in children. Pediatrics, 2004;113 (3 Pt 1) :e217-220.

9. Eichenfield LF, Funk A, FallonFriedlander S, Cunningham BB. A clinical study to evaluate the efficacy of ELA-Max (4\% liposomal lidocaine) as compared with eutectic mixture of local anesthetics cream for pain reduction of venipuncture in children. Pediatrics, 2002;109 (6):10931099.

10. Buckley MM, Benfield P. Eutectic lidocaine/prilocaine cream. A review of the topical anaesthetic/analgesic efficacy of a eutectic mixture of local anaesthetics (EMLA). Drugs. 1993; 46(1) :126-151.

11. Törüner E, Büyükgönenç L. Çocuk Sağlığı Temel hemşirelik yaklaşımları, Gökçe ofset, 2012; Ankara.

12. DeMore M, Cohen LL. Distraction for pediatric immunization, J Clin Psychol Med Settings, 2005;12: 281-292.

13. Cassidy KL, Reid GJ, McGrath PJ, Finley GA, Smith DJ, Morley C, Szudec EA, Morton M. Watch needle, watch TV: audovisual distraction in preschool immunization. Pain Mad., 2002;3: 108-118.

14. Cohen LL, Blount RL, Panopoulos G. Nurse coaching and cartoon distraction: an effective and practical intervention to reduce child, parent, and nurse distress HSP 2015;2(3):372-378 during immunizations. J Pediatr Psychol., 1997;22: 355-370.

15. Manimala R, Blount RL, Cohen LL. The effects of parental reassurance versus distraction on child distress and coping during immunizations. Child Health Care, 2000;29: 161-177.

16. French GM, Painter EC, Coury DL. Blowing away shot pain: a technique for pain management during immunization. Pediatrics, 1994;93(3): 384-388.

17. Sparks L. Taking the "ouch" out of injections for children. MCN Am J Matern Child Nurs., 2001;26: 72-78.

18. Gonzalez JC, Routh DK, Armstrong FD. Effect of maternal distraction versus reassurance on children's reactions to injections. J Pediatr Psychol., 1993;18: 593600.

19. Mason S, Johnson MH, Wooley C. A comparison of distractors for controlling distress in young children during medical procedures. J Clin Psychol Med, 1999;6: 239-248,

20. Sander Wint SS, Eshelman D, Steele J, Guzzetta CE. Effects of distraction using virtual reality glasses during lumbar punctures in adolescents with cancer. Oncol Nurs Forum, 2002;29:8-15.

21. Güdücü TF, Çelebioğlu $A$, Küçükoğlu $S$. Turkish children loved distraction: using kaleidoscope to reduce perceived pain during venipuncture. Journal of Clinical Nursing, 2009;18, 2180-2186.

22. İnal $\mathrm{S}$, Kelleci $\mathrm{M}$. Distracting children during blood draw: Looking through distraction cards is effective in pain relief of children during blood draw. International Journal of Nursing Practice; 2012;18(2), 210-219.

23. Weisenberg $M, \operatorname{Raz} T$, Hener $T$. The influence of film-induced mood on pain perception. Pain, 1998;76: 365-375.

24. De Wied M, Verbaten MN. Affective pictures processing, attention and pain tolerance. Pain, 2001;90: 163-72.

25. Landolt M A, Marti D, Widmer J, Meuli M. Does Cartoon Movie Distraction Decrease Burned Children's Pain Behavior? Journal of Burn Care \& Rehabilitation; 2002;23 (1): 61-65.

26. Dovney LV, ve Zun LS. The impact of watching cartoons for distraction during painful procedures in the emergency 
department Pediatr Emerg Care, 2012;28 (10):1033-5. doi:

10.1097/PEC.0b013e31826cac1a.

27. Bellieni CV, Cordellli DM, Raffaelli M, Ricci B, Morgese G, Buonocore G. Analgesic effect of watching TV during venipuncture. Arch Dis Child, 2006;91: 1015-1017.

28. Wang ZX, Sun LH, Chen AP. The efficacy of nonpharmacological methods of pain management in school age children receiving venepuncture in a paediatric department: a randomized controlled trial of audiovisual distraction and routine psychological intervention. Swiss Medical Weekly, 2008;138 (39-40):579-84.

29. Manne S L, Redd WH, Jacobsen PB, Gorfinkle K, Schorr O, Rapkin B. Behavioral intervention to reduce child and parent distress during venipuncture. Journal of Consulting and Clinical Psychology, 1990;58: 565-572.

30. Blount RL, Bachanas P J, Powers S W, Cotter M C, Franklin A, Chaplin W, Mayfield J, Henderson M, Blount S D. Training children to cope and parents to coach themduring routine immunizations: Effects on child, parent, and staff behaviors, Behavior Therapy, 1992;23 (4): 689-705.

31. Gupta D, Agarwal A, Dhiraaj S, Tandon M, Kumar M, Singh R, Singh P, Singh U. An Evaluation of Efficacy of Balloon Inflation on Venous Cannulation Pain in Children: A Prospective, Randomized, Controlled Study Anesthesia \& Analgesia, 2006;102 (5):1372-1375.

32. Klassen JA, Liang Y, Tjosvold L, Klassen TP, Hartling L. Music for pain and anxiety in children undergoing medical procedures: a systematic review of randomized controlled trials. Ambulatory Pediatrics, 2008;8:117-128.

33. Press J, Gidron Y, Maimon M, Gonen A, Goldman V, Buskia D. Effects of active distraction on pain of children undergoing venipuncture: who benefits from it? The Pain Clinic, 2003;15: 261-269.

34. Fowler-Kerry S, Lander JR. Management of injection pain in children, Pain, 1987;30(2): 169-175.

35. Balan R, Bavdekar SB, Jadhav S. Can Indian classical instrumental music reduce pain felt during venepuncture? Indian Journal of Pediatrics, 2009;76:469-473.
36. Caprilli S, Anastasi F, Grotto RP, Scollo $\mathrm{M}$, Messeri A. Interactive music as a treatment for pain and stress in children during venipuncture: A randomized prospective study. Journal of Developmental and Behavioral Pediatrics, 2007;28:399-403.

37. Kristjansdottir O, Kristjansdottir G. Randomized clinical trial of musical distraction with and without headphones for adolescents' immunization pain. Scandinavian Journal of Caring Sciences, 2011;25:19-26.

38. Nguyen TN, Nilsson S, Hellstrom A-L, Bengtson A. Music therapy to reduce pain and anxiety in children with cancer undergoing lumbar puncture: A randomized clinical trial. Journal of Pediatric Oncology Nursing, 2010;27 (3):146-155

39. Lange B, Williams M, Fulton I. Virtual Reality distraction during pediatric medical procedures, Pediatric Pain Letter, 2006;8 (1) :6-10.

40. Sander Wint SS, Eshelman D, Steele J, Guzzetta CE. Effects of distraction using virtual reality glasses during lumbar punctures in adolescents with cancer. Oncol Nurs Forum, 2002;29: E8-15.

41. Vessey JA, Carlson KL \& McGill J. Use of distraction with children during an acute pain procedure. Nursing Research, 1994;43: 369-372.

42. Carlson KL, Broome $M$ \& Vessey JA. Using distraction to reduce reported pain, fear and behavioral distress in children and adolescents: a multisite study. Journal of the Society of Pediatric Nurses, 2000;5: 75-85.

43. Hasanpour M, Tootoonchi M, Aein F \& Yadegarfar G. The effects of two nonpharmacologic pain management methods for intramuscular injection pain in children. Acute Pain, 2006;8: 7-12. 